\title{
The Dynamic Analysis of China's Agricultural Economic Growth
}

\author{
Wu Mingran ${ }^{1,2}$, Zhao Min ${ }^{1,2}$, Wu Zhaodan ${ }^{3}$ \\ ${ }^{1}$ School of Business, Hohai University, Nanjing, China \\ ${ }^{2}$ Science and Technology System Reform Think Tank of Jiangsu Province, Nanjing, China \\ ${ }^{3}$ School of Business Administration, Hohai University, Changzhou, China
}

Email address:

wumr1992@163.com (Wu Mingran)

\section{To cite this article:}

Wu Mingran, Zhao Min, Wu Zhaodan. The Dynamic Analysis of China's Agricultural Economic Growth. International Journal of Economy, Energy and Environment. Vol. 4, No. 6, 2019, pp. 106-117. doi: 10.11648/j.ijeee.20190406.11

Received: October 15, 2019; Accepted: November 17, 2019; Published: December 4, 2019

\begin{abstract}
Based on time series data from 1990 to 2016, an empirical analysis examined the factors affecting China's agricultural economic growth by developing a vector auto-regressive model (VAR), impulse response function (IRF) and variance decomposition function (VD). The results show that Chinese agriculture lacks long-term support factor. During the study period, an increase in the fixed asset investment, the total agricultural machinery power, the amount of chemical fertilizer used, and the education level of the rural labor force contributed to agricultural economic growth. However, an increase in the size of the agricultural labor force and in the total area under cultivation was not conducive to agricultural economic growth. In addition, China's agricultural economic growth was overly dependent on financial investment, while the contribution of other factors was relatively small. China's agricultural economy clearly has experienced extensive development. Hence, in the next development period, the Chinese government needs to increase agricultural fixed asset investment and strengthen its oversight. In addition, the government needs to strengthen its support of agricultural mechanization, set reasonable limits on the use of chemical fertilizers and, more importantly, focus on improvement in the quality of agricultural products and the accumulation of human capital.
\end{abstract}

Keywords: Agricultural Economic Growth, Fixed Asset Investment, Agricultural Labor Force Size,

Total Power of Agricultural Mechanization, Fertilizer Application Amount, Total Area Under Cultivation, Human Capital

\section{Introduction}

Agriculture is the base of the national economy and plays an indispensable role in food security and social stability. Since the reform and opening up of its economy, China's agriculture has developed rapidly and achieved great advances. These advances, however, obscure many problems, such as the low production efficiency and modernization, the lack of agricultural resources and disaster management capabilities, the significant decline in the agricultural labor force, and the degeneration of the ecological environment. These factors make it difficult to maintain the development of traditional agriculture. The question of how to develop the agricultural economy in a healthy, stable, and sustainable way has become a focus of academic research in recent years. According to the classical theory of economic development, economic growth mainly depends on an increase in material inputs and production efficiency. Therefore, this paper believes that the economic growth of agriculture is mainly driven by the labor force (including labor force size and human capital), material inputs (including natural resource input and capital input) and technological progress.

Based on this theory, the paper uses the Cobb-Douglas production function, assigns indicators to represent material inputs, labor force and technical level, respectively, and explores the relationship between these different indicators and the growth of the agricultural economy by using empirical approaches, such as stability testing, general impulse response function and variance decomposition. The purpose is to determine the dynamic characteristics of China's agricultural economic growth in recent years and to determine an effective way for China to improve sustainable agricultural development. 


\section{Literature Review}

In recent years, most academic analyses of agricultural growth have focused on five levels: (1) The level of geographic location and natural resources. Several studies found that geographic location plays an important role in agricultural economic growth and that scale and agglomeration externalities are also important forces affecting economic growth. To a certain extent, economic growth has resulted in the geographical concentration of economic activities, and that geographical concentration, in turn, has further promoted economic growth [1-2]. In terms of research on natural resources, academic research has primarily focused on water and land [3-8]. The studies have found that water and land resources are highly important and are indispensable material elements of agricultural economic development. A good match between water and land resources can transform regional resource advantages into economic growth. However, there is a spatial mismatch of agricultural water resources and land resources in China, which has caused damage to agricultural production. In addition, the regions where agricultural water and land resource are formed and consumed do not match spatially, which has resulted in loss of agricultural economic growth. (2) The level of material inputs. In this level, most research focuses on the effect of fiscal expenditure on agricultural economic growth [9-14]. The studies found that fiscal expenditure does have an impact on agricultural economic growth. That impact is divided into direct effects and indirect spillover effects, and there are obvious spatial differences between these two effects in different regions. Therefore, to increase financial efficiency and accelerate agricultural development, the government should invest heavily in areas with great output flexibility. (3) The level of technology innovation. The relationship between scientific and technological progress and agricultural economic growth has long been a focus of academia's attention [15-23]. The results show that scientific and technological progress can effectively stimulate agricultural economic growth. However, studies have also shown that the impact of a unilateral increase in agricultural science and technology is limited. Optimizing the allocation of science and technology resources is more important than unilaterally increasing investment in agricultural science and technology. (4) The level of human capital. Since [24] formally proposed the concept of human capital, the question of whether rural human capital has an impact on the growth of agricultural economy and the nature of the impact has been heavily researched. Proponents of the endogenous growth theory in particular placed great emphasis on human capital performance. Most scholars perform an empirical analysis by improving on the traditional Cobb-Douglas production function and find that the accumulation and enrichment of human capital can promote economic growth effectively [25-29]. However, several scholars have noted that rural talent is particularly prone to migrating to urban areas, which has caused the impact of human capital on agricultural output to be insignificant or even negative. A number of scholars refer to this phenomenon in rural areas as the "Human-Capital Trap" [30-32]. (5) The effect of some other socio-economic activities on agricultural economic growth. Studies have found that the income gap between urban and rural [33], the urbanization process [34], import and export trade [35], rural education level (Ji Q H, 2017) [36], rural finance [37-38], agricultural industry structure [39] and some other social and economic factors affect agricultural economic growth to a certain extent. The academic research on this topic is abundant, and the existing outcomes are important references for this paper. However, there is still room for improvement in the existing research: First, existing studies typically discuss the unilateral effects of a particular factor on agricultural economic growth through the use of simultaneous equations, and the conclusions often describe a unilateral causal relationship, ignoring the complex bilateral relationship between agricultural economic growth and these factors. Second, the existing studies primarily discuss the impact of an isolated factor on agricultural economic growth, and there is notably little discussion in the literature of multiple factors at the same time, which limits the research perspective. Therefore, this paper tries to compensate for the deficiencies in the existing research in two ways. First, the vector auto-regressive model is used to accurately quantify the long-term interaction between agricultural economic growth and its influencing factors. Second, indicators are selected to represent natural resources, material capital, human capital, technological progress, and agricultural economic growth, and these indicators are used in a discussion framework to simultaneously analyze the impact of the different factors on agricultural economic growth.

\section{Selection of Variables and Research Methods}

\subsection{Selection of Variable and DATA}

Applying the Cobb-Douglas production function, this paper discusses the influence of different production factors on the development of China's agricultural economy. For scientific verification, we select indicators to represent the different variables. For the independent variables, we use the agricultural fixed asset investment input $\left(\mathrm{X}_{1}\right)$ to represent the government's support for agriculture, the size of the agricultural labor force $\left(\mathrm{X}_{2}\right)$ to represent agricultural labor factors input, and the total power of agricultural mechanization $\left(\mathrm{X}_{3}\right)$ to represent the mechanical operations input, and the amount of fertilizer $\left(\mathrm{X}_{4}\right)$ to represent the fertilizer input, and the total sown area $\left(\mathrm{X}_{5}\right)$ to represent the land resources input, and the education level of the rural labor force $\left(\mathrm{X}_{6}\right)$ to represent the quality of labor input. For the dependent variable, this paper uses the gross output value of agriculture (y) to reflect the agricultural economic production in a certain period. Most of the variable data are from the China Statistical Yearbook, China Rural Statistical Yearbook and China's Agricultural Statistics Collection from 1991 to 2017. 
Table 1. Description of variables.

\begin{tabular}{lllll}
\hline Variable Type & $\begin{array}{l}\text { Variable } \\
\text { Symbol }\end{array}$ & Variable Description & Unit & Note \\
\hline Dependent Variable & $\mathrm{y}$ & Agricultural Gross Output Value & Billion & Statistical Yearbook Interpretation Index \\
& $\mathrm{X}_{1}$ & Investment in Agricultural Fixed Assets & Billion & Statistical Yearbook Interpretation Index \\
& $\mathrm{X}_{2}$ & Agricultural Labor Figures & 10,000 people & Statistical Yearbook Interpretation Index \\
Independent & $\mathrm{X}_{3}$ & Total Power of Agricultural Mechanization & $10,000 \mathrm{KW}$ & Statistical Yearbook Interpretation Index \\
Variable & $\mathrm{X}_{4}$ & Use of Chemical Fertilizers & $10,000 \mathrm{t}$ & Statistical Yearbook Interpretation Index \\
& $\mathrm{X}_{5}$ & Total Sown Area & $\mathrm{khm}^{2}$ & Statistical Yearbook Interpretation Index \\
& $\mathrm{X}_{6}$ & Education Level of Rural Labor & man & The number of people with an education level above \\
& & & & high school in every 100,000 people in rural areas \\
\hline
\end{tabular}

\subsection{Research Methods}

Before performing an in-depth analysis of the relationship between various influencing factors and agricultural economic growth, this paper first uses stability testing to examine whether there are long-term stable relationships between different variables and later uses the generalized impulse response function to describe the dynamic and interactive relationships between variables. Finally, the method of variance decomposition is applied to quantify the relative importance of the various variables regarding impact on agricultural economic growth. In addition, since the logarithmic treatment does not change the structure of the data itself and can smooth the index, effectively eliminating the heteroscedasticity, the study applies the logarithmic process to the above-referenced indicators and denotes them as $\ln \mathrm{X}_{1}$, $\ln \mathrm{X}_{2}, \ln \mathrm{X}_{3}, \ln \mathrm{X}_{4}, \ln \mathrm{X}_{5}, \ln \mathrm{X}_{6}$ and $\ln \mathrm{y}$, respectively.

(1) Vector Auto-Regression Model

Traditional econometrics often use the economic theory and structural methods to establish the model to describe the structural relationship between different variables. However, this method has been questioned as having many disadvantages. The traditional economic theory does not provide a sufficiently rigorous explanation for the dynamic linkages between variables, making estimation and inference so complicated. After the development of modern econometrics, Smis A C [40] proposed a non-structural method to establish the model between economic variables, known as the vector auto-regression model (VAR). The model is not based on economic theory but on the statistical nature of data and constructs each variable in the economic system as a function of the lagged variable of all variables. The general form of the VAR model is:

$$
Y_{t}=\sum_{i=1}^{p} A_{i} Y_{t-i}+\varepsilon_{t}
$$

In this equation, $Y_{t}$ is the n-dimensional endogenous variable vector formed by the $\mathrm{t}_{\mathrm{th}}$ observation value, $A_{i}$ is an $\mathrm{n} \times \mathrm{n}$ coefficient matrix, $\mathrm{p}$ is the lag phase for endogenous variables, and $\varepsilon_{t}$ is the n-dimensional random perturbation term. In addition, $\varepsilon_{i}(\mathrm{i}=1,2, \ldots, \mathrm{n})$ satisfied $\operatorname{Cov}\left(\varepsilon_{t}, \varepsilon_{s}\right)=$ $0(t \neq s)$.

(2) Impulse Response Function

This paper uses the impulse response function to describe the long-term dynamic relationship between various influencing factors and agricultural economic growth. In practice, since the VAR model is a non-theoretical model, we do not often use it to analyze how a change in one variable affects another variable. Instead, we analyze the performance of the dynamic system when affected by the change of an error term or a certain type of shock, and this method is called the impulse response function (IRF). The general form of the IRF model is:

$$
I_{y}\left(n, \delta, \omega_{t-1}\right)=E\left[Y_{t+n} \mid \varepsilon_{t}=\delta, \varepsilon_{t+1}=0, \ldots, \varepsilon_{t+n}=0, \omega_{t-1}\right]-E\left[Y_{t+n} \mid \varepsilon_{t}=0, \varepsilon_{t+1}=0, \ldots ., \varepsilon_{t+n}=0, \omega_{t-1}\right]
$$

In this formula, $\mathrm{n}$ is the impact response series, $\delta$ is the impact from variables, $\omega_{t-1}$ is all available information when the shock occurs, $I_{Y}$ the $\mathrm{n}_{\text {th }}$ impulse response value, and $E$ is the expectation.

(3) Variance Decomposition

Variance decomposition is a method for further evaluating the importance of different structural impacts of endogenous variables. The basic idea is to decompose the predicted mean square error (MSE) of each endogenous variable in the system into related parts and then determine the relative contribution of each perturbation to the overall variance. Thus, we can calculate the relative importance of each information to the endogenous variables in the model. The model's prediction variance is:

$$
\varepsilon_{t+s}+\varphi_{1} \varepsilon_{t+s-1}+\varphi_{2} \varepsilon_{t+s-2}+\cdots+\varphi_{s-1} \varepsilon_{t+1}
$$

Its mean square error is:

$$
\Omega+\varphi_{1} \Omega \varphi_{1}^{\prime}+\cdots+\varphi_{s-1} \Omega \varphi_{s-1}^{\prime}=p p^{\prime}+\varphi_{1} p p^{\prime} \varphi_{1}+\cdots+\varphi_{1} p p^{\prime} \varphi_{s-1}
$$

In the formula, $p p^{\prime}=\Omega$. Based on the above equation, the prediction of the mean square error of each endogenous variable can be decomposed into the impact contribution value of the variable, and the relative importance of each variable's impact is calculated. This research uses the variance decomposition method to measure the degree of interaction between various influencing factors and agricultural economic growth. 


\section{Empirical Analysis of the Relationship between Agricultural Economic Growth and Various Factors}

\subsection{Stationarity Test of Variables}

In this research, we construct the VAR system between agricultural economic growth and various influencing factors, and we establish six distinct bivariate VAR models. Using the data presented above, the study first uses Eviews (Version 7.2) to test the stability of each variable following the augmented dickey-fuller test (ADF) method, which is also the most commonly used method in this academic field. Given the limited sample size, the maximum lag order of this study is three, and the test results are shown in Table 2.

Table 2. Unit root test $(A D F)$ results of variable sequences.

\begin{tabular}{|c|c|c|c|c|c|c|c|c|c|}
\hline $\begin{array}{l}\text { Variable } \\
\text { Sequence }\end{array}$ & ADF Test Value & $\begin{array}{l}5 \% \text { Significant } \\
\text { Level }\end{array}$ & Lag & Result & $\begin{array}{l}\text { Variable } \\
\text { Sequence }\end{array}$ & ADF Test Value & $\begin{array}{l}5 \% \text { Significant } \\
\text { Level }\end{array}$ & Lag & Result \\
\hline $\operatorname{lny}$ & -1.25 & -2.981 & 0 & non-stationary & $\Delta \ln X_{3}$ & -2.107 & -2.986 & 0 & non-stationary \\
\hline$\Delta \ln y$ & -2.784 & -2.986 & 0 & non-stationary & $\Delta^{2} \ln X_{3}$ & -5.632 & -2.992 & 0 & stationary \\
\hline$\Delta^{2} \ln y$ & -4.573 & -2.998 & 1 & stationary & $\ln X_{4}$ & -2.29 & -3.005 & 4 & non-stationary \\
\hline $\ln X_{1}$ & -1.233 & -2.981 & 0 & non-stationary & $\Delta \ln \mathrm{X}_{4}$ & -2.365 & -2.986 & 0 & non-stationary \\
\hline$\Delta \ln \mathrm{X}_{1}$ & -3.53 & -2.986 & 0 & stationary & $\Delta^{2} \ln \mathrm{X}_{4}$ & -3.012 & -2.806 & 3 & stationary \\
\hline $\ln X_{2}$ & -0.533 & -2.986 & 1 & non-stationary & $\ln X_{5}$ & -0.021 & -2.981 & 0 & non-stationary \\
\hline$\Delta \ln X_{2}$ & -1.859 & -2.986 & 0 & non-stationary & $\Delta \ln \mathrm{X}_{5}$ & -3.629 & -2.986 & 0 & stationary \\
\hline$\Delta^{2} \ln \mathrm{X}_{2}$ & -3.998 & -2.992 & 0 & stationary & $\ln \mathrm{X}_{6}$ & -1.799 & -2.986 & 1 & non-stationary \\
\hline $\ln X_{3}$ & -1.501 & -2.981 & 0 & non-stationary & $\Delta \ln \mathrm{X}_{6}$ & -3.38 & -2.986 & 0 & stationary \\
\hline
\end{tabular}

Note: $\Delta$ represents the first order difference, $\Delta^{2}$ represents the second order difference.

The test results show that there is a unit root at the significance level of $5 \%$ for all variables, which means that they do not pass the significance test. Under the condition of the first-order difference, only $\ln \mathrm{X}_{1}, \ln \mathrm{X}_{5}$, and $\ln \mathrm{X}_{6}$ pass the unit root test, which means they are a stationary sequence. The other four variables passed through the unit root process are all under the second-order difference. Therefore, we reject the original hypothesis of the unit root existence, all variables are stable in a time series, and there is also a cointegration relationship among variables. Thus, there is a long-term equilibrium relationship between China's agricultural economic growth and various factors.

\subsection{Foundation of the Vector Autoregressive Model}

The VAR model presented in this paper contains seven variables, which are the inputs of agricultural fixed asset investment, size of the agricultural labor force, total power of agricultural mechanization, amount of chemical fertilizers used, total sown area and educational level of rural labor together with the output of China's agricultural economy. In addition, this paper presents six different independent vector autoregressive models. According to the principle of "the AIC value is smaller and the better" in the AIC information criterion (Akaike), the lag order of the model is selected as two. Eviews (Version 7.2) is used to estimate the parameters of the dynamic equation. The results are shown in Table 3.

Table 3. Auto-regression parameter estimates of Chinese agricultural economic growth and vector values of various elements.

\begin{tabular}{|c|c|c|c|c|}
\hline Variable Sequence & Iny & $\ln X_{1}$ & $\ln X_{2}$ & $\ln X_{3}$ \\
\hline Lny (-1) & $0.865718(0.59945)$ & $-0.292(0.67268)$ & $-0.1654(0.12522)$ & $-0.0158(0.05672)$ \\
\hline Lny (-2) & $-0.3773(0.50793)$ & $0.280594(0.56998)$ & $0.054563(0.1061)$ & $-0.0745(0.04806)$ \\
\hline $\ln X_{1}(-1)$ & $0.066906(0.29066)$ & $0.361573(0.32616)$ & $-0.0615(0.06071)$ & $0.033198(0.02750)$ \\
\hline $\ln X_{1}(-2)$ & $-0.0198(0.33951)$ & $-0.1229(0.38098)$ & $0.060636(0.07092)$ & $0.032125(0.03212)$ \\
\hline $\ln X_{2}(-1)$ & $-1.371(1.09131)$ & $1.655003(2.01014)$ & $1.56566(0.37418)$ & $-0.1024(0.16949)$ \\
\hline $\ln X_{2}(-2)$ & $0.843252(1.05277)$ & $-2.9407(2.19132)$ & $-0.7999(0.4079)$ & $0.062909(0.18477)$ \\
\hline $\ln X_{3}(-1)$ & $1.044660(1.25036)$ & $-0.6269(1.52527)$ & $-0.1986(0.47007)$ & $0.363434(0.21293)$ \\
\hline $\ln X_{3}(-2)$ & $-0.6741(1.5593)$ & $2.843842(1.74978)$ & $0.142908(0.32571)$ & $0.128267(0.14754)$ \\
\hline $\ln \mathrm{X}_{4}(-1)$ & $1.971295(1.13633)$ & $0.948216(1.51947)$ & $0.388493(0.65513)$ & $0.335243(0.29675)$ \\
\hline $\ln X_{4}(-2)$ & $-1.1037(0.2003)$ & $1.472156(0.46909)$ & $0.156658(0.45961)$ & $0.207711(0.20819)$ \\
\hline $\ln \mathrm{X}_{5}(-1)$ & $-4.6415(0.84006)$ & $-1.5323(1.187)$ & $0.264340(0.59325)$ & $0.402939(0.26872)$ \\
\hline $\ln X_{5}(-2)$ & $2.751369(1.38422)$ & $-5.7954(1.79764)$ & $-1.0066(0.70691)$ & $-0.4814(0.32021)$ \\
\hline $\ln \mathrm{X}_{6}(-1)$ & $-0.4594(0.80498)$ & $-0.0891(0.90332)$ & $-0.0177(0.16815)$ & $0.012345(0.07617)$ \\
\hline $\ln \mathrm{X}_{6}(-2)$ & $0.21681(0.47498)$ & $-0.3701(0.53301)$ & $-0.0676(0.09922)$ & $0.064707(0.04494)$ \\
\hline $\mathrm{C}$ & $23.39867(0.365)$ & $66.11474(0.9068)$ & $9.156149(1.47606)$ & $2.232993(0.29236)$ \\
\hline R-squared & 0.996433 & 0.999231 & 0.997794 & 0.999917 \\
\hline
\end{tabular}


Table 3. Coutinued.

\begin{tabular}{llll}
\hline Variable Sequence & $\ln \mathbf{X}_{\mathbf{4}}$ & $\ln \mathbf{X}_{\mathbf{5}}$ & $\ln \mathbf{X}_{\mathbf{6}}$ \\
\hline Lny $(-1)$ & $0.155032(0.09801)$ & $0.096652(0.06099)$ & $0.19247(0.36675)$ \\
Lny $(-2)$ & $0.036275(0.08304)$ & $-0.0131(0.05168)$ & $0.343247(0.31076)$ \\
$\ln \mathrm{X}_{1}(-1)$ & $0.003142(0.04752)$ & $0.031133(0.02957)$ & $-0.0796(0.17783)$ \\
$\ln \mathrm{X}_{1}(-2)$ & $-0.0076(0.05551)$ & $0.025828(0.03454)$ & $0.035968(0.20771)$ \\
$\ln \mathrm{X}_{2}(-1)$ & $-0.3176(0.29287)$ & $0.398982(0.18226)$ & $0.040337(1.09594)$ \\
$\ln \mathrm{X}_{2}(-2)$ & $0.517(0.31927)$ & $-0.3593(0.19869)$ & $1.032697(1.19473)$ \\
$\ln \mathrm{X}_{3}(-1)$ & $0.319149(0.36792)$ & $-0.2211(0.22897)$ & $0.287444(1.3768)$ \\
$\ln \mathrm{X}_{3}(-2)$ & $-0.2068(0.25494)$ & $-0.0461(0.15865)$ & $0.708374(0.95399)$ \\
$\ln \mathrm{X}_{4}(-1)$ & $0.088649(0.51277)$ & $0.374523(0.31911)$ & $-2.2638(1.91884)$ \\
$\ln \mathrm{X}_{4}(-2)$ & $0.244767(0.35974)$ & $-0.4716(0.22387)$ & $1.279657(1.34617)$ \\
$\ln \mathrm{X}_{5}(-1)$ & $-0.7709(0.46433)$ & $0.19346(0.28897)$ & $-1.5593(1.73758)$ \\
$\ln \mathrm{X}_{5}(-2)$ & $0.145341(0.5533)$ & $0.38543(0.34434)$ & $-2.7762(1.0705)$ \\
$\ln \mathrm{X}_{6}(-1)$ & $-0.0354(0.13161)$ & $-0.0798(0.0819)$ & $0.438895(0.4925)$ \\
$\ln \mathrm{X}_{6}(-2)$ & $0.034585(0.07766)$ & $0.1143(0.04833)$ & $-0.0672(0.2906)$ \\
$\mathrm{C}$ & $7.938652(0.41693)$ & $6.855451(0.61577)$ & $38.28452(1.7548)$ \\
$\mathrm{R}$-squared & 0.999008 & 0.986639 & 0.99683 \\
\hline
\end{tabular}

Note: The variables in brackets indicate the standard error.

As an initial matter, based on the value of the model's R-squared, this model has a good degree of fit. Relative to the variable of agricultural economic growth (lny), agricultural fixed asset investment $\left(\ln \mathrm{X}_{1}\right)$ and total agricultural mechanization power $\left(\ln \mathrm{X}_{3}\right)$ are both positive in the case of the lag phase I, and negative in the lag phase II, indicating that these two factors did not have strong effects on agricultural economic growth in the earlier period but did in the later period. In addition, the size of the rural labor force $\left(\ln \mathrm{X}_{2}\right)$, the fertilizer application amount $\left(\ln \mathrm{X}_{4}\right)$, the total acreage of crops $\left(\ln \mathrm{X}_{5}\right)$ and the education level of rural labor $\left(\ln \mathrm{X}_{6}\right)$ are negative in the lag phase I, and positive in the lag phase II, indicating that these variables stimulate economic growth more in the early stages. Thus, China's agricultural economy lacks a long-lasting stimulus.

In addition, for the regression, all of the root modes are less than 1 (as shown in Table 4) and in the unit circle (as shown in Figure 1), which means that the model is stable. Therefore, we can conclude that although the variables of agricultural economic growth and various influencing factors showed a complex and ever-changing relationship during the research period, these variables still formed a stable system.

Table 4. Lag structure test of VAR model.

\begin{tabular}{ll}
\hline Root & Modulus \\
\hline $0.969725-0.102111 \mathrm{i}$ & 0.975086 \\
$0.969725+0.102111 \mathrm{i}$ & 0.975086 \\
$0.783236-0.345307 \mathrm{i}$ & 0.855976 \\
$0.783236+0.345307 \mathrm{i}$ & 0.855976 \\
$0.450236-0.607938 \mathrm{i}$ & 0.756506 \\
$0.450236+0.607938 \mathrm{i}$ & 0.756506 \\
$0.189303-0.692445 \mathrm{i}$ & 0.717855 \\
$0.189303+0.692445 \mathrm{i}$ & 0.717855 \\
$-0.480939-0.403462 \mathrm{i}$ & 0.627761 \\
$-0.480939+0.403462 \mathrm{i}$ & 0.627761 \\
-0.5278 & 0.527804 \\
$0.321146-0.382664 \mathrm{i}$ & 0.499566 \\
$0.321146+0.382664 \mathrm{i}$ & 0.499566 \\
-0.06022 & 0.060217 \\
\hline
\end{tabular}

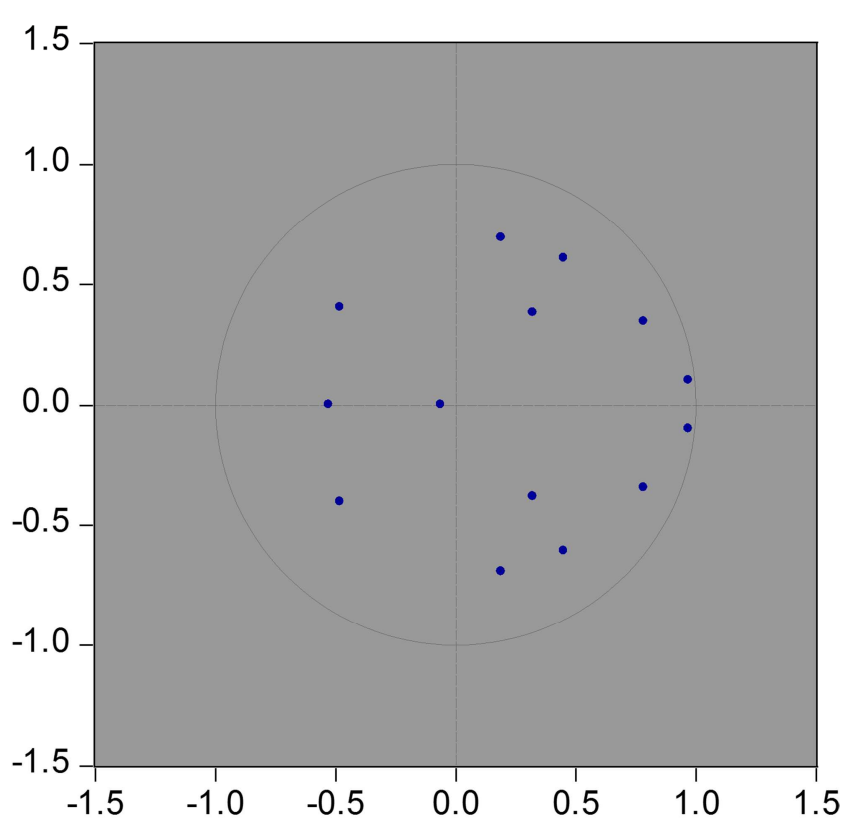

Figure 1. VAR model characteristic polynomial roots reciprocal.

\subsection{Generalized Impulse Response Analysis}

Impulse response analysis is often used to describe the effect of the current and future values of endogenous variables after being shocked by a standard deviation sized impact on the random error term. Using this method, this paper describes the dynamic impact trajectories between agricultural economic growth and influencing factors, and it characterizes the long-term, dynamic relationship among these variables. In the analysis diagram, the solid line represents the impulse response function, and the dotted line represents the deviation band with double positive and negative standard deviations. For purposes of this analysis, the impact response period is set to 10 . The results of the analysis are shown in Table 5 . 
Table 5. Results of the generalized impulse response analysis

\begin{tabular}{|c|c|c|c|c|c|c|}
\hline period & $\begin{array}{l}\text { Response of Iny to } \\
\ln x_{1}\end{array}$ & $\begin{array}{l}\text { Response of } \ln x_{1} \text { to } \\
\ln y\end{array}$ & $\begin{array}{l}\text { Response of Iny to } \\
\ln x_{2}\end{array}$ & $\begin{array}{l}\text { Response of } \ln x_{2} \text { to } \\
\text { lny }\end{array}$ & $\begin{array}{l}\text { Response of Iny to } \\
\ln x_{3}\end{array}$ & $\begin{array}{l}\text { Response of } \ln x_{3} \text { to } \\
\text { Iny }\end{array}$ \\
\hline 1 & 0 & -0.035 & 0 & -0.007 & 0 & 0 \\
\hline 2 & -0.004 & -0.037 & -0.016 & -0.016 & 0.002 & 0.001 \\
\hline 3 & 0.005 & -0.007 & -0.05 & -0.022 & 0.007 & 0 \\
\hline 4 & 0.011 & 0.021 & -0.055 & -0.024 & 0.007 & -0.002 \\
\hline 5 & 0.014 & 0.054 & -0.034 & -0.022 & 0.007 & 0.002 \\
\hline 6 & 0.011 & 0.067 & -0.012 & -0.017 & 0.006 & 0.004 \\
\hline 7 & 0.007 & 0.065 & 0.005 & -0.01 & 0.004 & 0.004 \\
\hline 8 & 0.003 & 0.048 & 0.013 & -0.003 & 0.003 & 0.003 \\
\hline 9 & -0.001 & 0.018 & 0.017 & 0.003 & 0.002 & 0 \\
\hline 10 & -0.005 & -0.011 & 0.02 & 0.008 & 0.002 & -0.004 \\
\hline Adding & 0.042 & 0.181 & -0.112 & -0.111 & 0.040 & 0.011 \\
\hline
\end{tabular}

Table 5. Coutinued.

\begin{tabular}{|c|c|c|c|c|c|c|}
\hline period & $\begin{array}{l}\text { Response of Iny to } \\
\ln x_{4}\end{array}$ & $\begin{array}{l}\text { Response of } \ln x_{4} \text { to } \\
\text { lny }\end{array}$ & $\begin{array}{l}\text { Response of Iny to } \\
\ln x_{5}\end{array}$ & $\begin{array}{l}\text { Response of } \ln x_{5} \text { to } \\
\ln y\end{array}$ & $\begin{array}{l}\text { Response of Iny to } \\
\ln x_{6}\end{array}$ & $\begin{array}{l}\text { Response of } \ln x_{6} \text { to } \\
\text { lny }\end{array}$ \\
\hline 1 & 0 & 0.008 & 0 & 0.001 & 0 & -0.014 \\
\hline 2 & 0.001 & 0.012 & -0.018 & 0.006 & -0.009 & -0.01 \\
\hline 3 & -0.003 & 0.015 & -0.017 & 0.002 & -0.001 & -0.004 \\
\hline 4 & 0 & 0.013 & -0.001 & 0.002 & 0.001 & -0.02 \\
\hline 5 & 0.003 & 0.01 & 0.003 & 0.004 & 0.004 & -0.026 \\
\hline 7 & 0.007 & 0.004 & -0.004 & 0.007 & 0.006 & -0.029 \\
\hline 8 & 0.006 & -0.002 & -0.009 & 0.007 & 0.006 & -0.031 \\
\hline 9 & 0.005 & -0.007 & -0.011 & 0.005 & 0.005 & -0.032 \\
\hline 10 & 0.005 & -0.011 & -0.011 & 0.002 & 0.004 & -0.03 \\
\hline Adding & 0.031 & 0.048 & -0.065 & 0.041 & 0.023 & -0.224 \\
\hline
\end{tabular}

(1) The dynamic relationship between agricultural fixed asset investment and agricultural economic growth

The impulse response results of agricultural fixed assets investment and agricultural economic growth are shown in Figure 2 and Table 5. We first note that the cumulative responses of lny and $\ln \mathrm{X}_{1}$ are both positive. From this finding, we can see that fixed asset investment in China's agriculture has a positive correlation with economic output, indicating that China's agricultural economic growth has a relatively rigid demand for financial investment. It also

Response of LNX1 to LNY

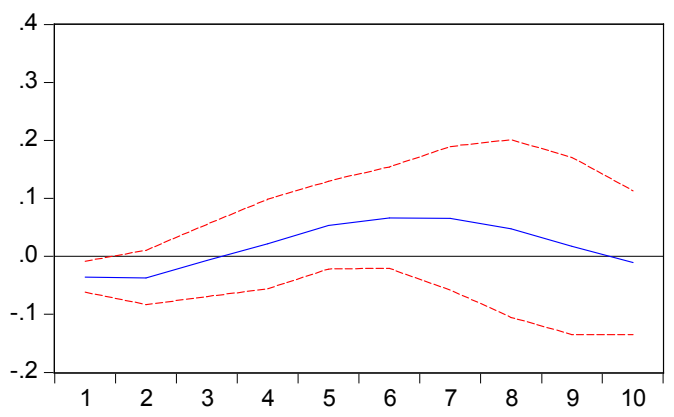

shows that China's agricultural economic growth is still relying too much on material inputs, thus presenting a clear characteristic of extensive. We emphasize that under the impact of agricultural fixed asset investment $\left(\ln \mathrm{X}_{1}\right)$, the agricultural economy (lny) displays a relatively small range of amplitude during the entire reaction period, indicating that the role of agricultural fixed asset investment in agricultural economic growth is limited and that the contribution ratio is low, which is a problem that needs to be solved.

Response of LNY to LNX1

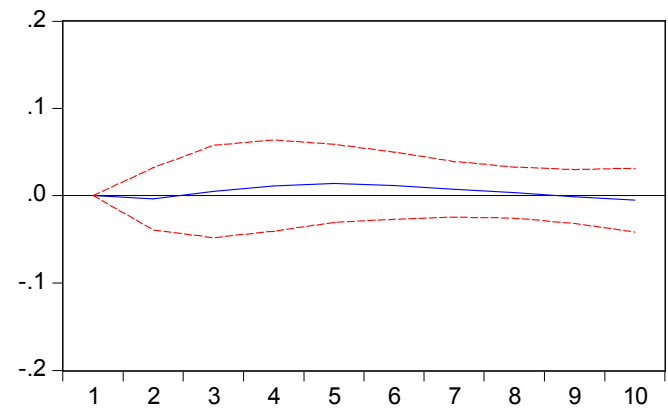

Figure 2. Impulse response curves of agricultural fixed asset investment and agricultural economic growth.

(2) The dynamic relationship between agricultural labor force and agricultural economic growth

The results of the impulse response analysis of agricultural labor force and agricultural economic growth are shown in Figure 3 and Table 5. We first note that the cumulative responses of $\ln \mathrm{X}_{2}$ and $\operatorname{lny}$ are both negative; therefore, there is a negative correlation between the agricultural labor quantity and the economic growth. This 
finding indicates that China's agricultural economy has developed to a high level. With continuous improvement in productivity and economic growth, the era of "many hands make light work" in agricultural production is over. Modern agriculture emphasizes efficiency and relies more on advances in science and technology, management skills and qualified personnel. From Figure 3, we can see that under the shock of $\ln X_{2}$, the reaction of lny in the base period is

Response of LNX2 to LNY

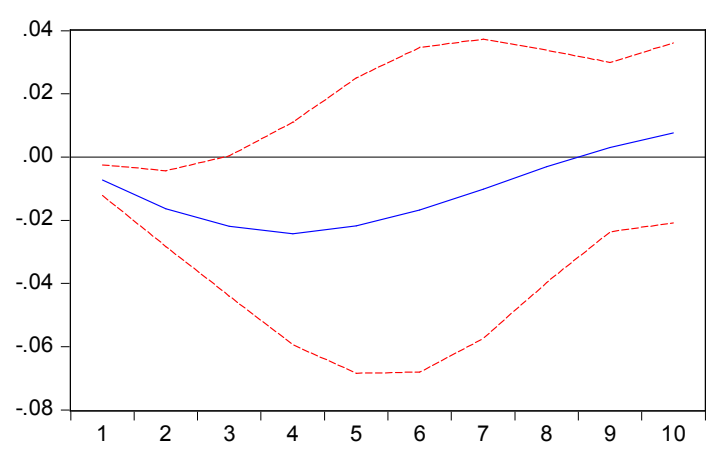

negative, and is not positive until the $7_{\text {th }}$ period, indicating that a reduction in the labor force number will cause some loss in agricultural economic growth initially. However, in the long term, this effect is positive. Under the shock of the $\ln y, \ln X_{2}$ is negative until the $9_{\text {th }}$ period. The reason for this result may be that as agricultural development and income increase, an increasing number of people are drawn to agriculture in the later period.

Response of LNY to LNX2

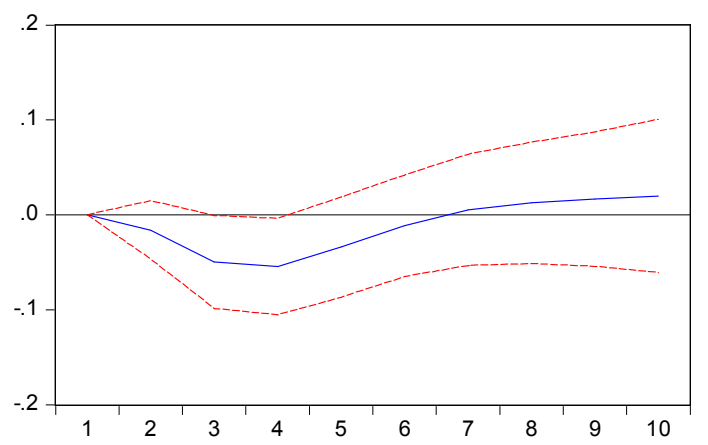

Figure 3. Impulse response curves of agricultural labor force size and agricultural economic growth.

(3) The dynamic relationship between agricultural machinery power and agricultural economic growth

The results of the impulse response analysis of the total power of agricultural machinery and the growth of the agricultural economy are shown in Figure 4 and Table 5. We first note that the cumulative responses of $\ln y$ and $\ln \mathrm{X}_{3}$ are both positive. We can conclude that there is a positive relationship between the development of mechanization and economic output, and we can also conclude that the development of China's agricultural mechanization will

Response of LNX3 to LNY

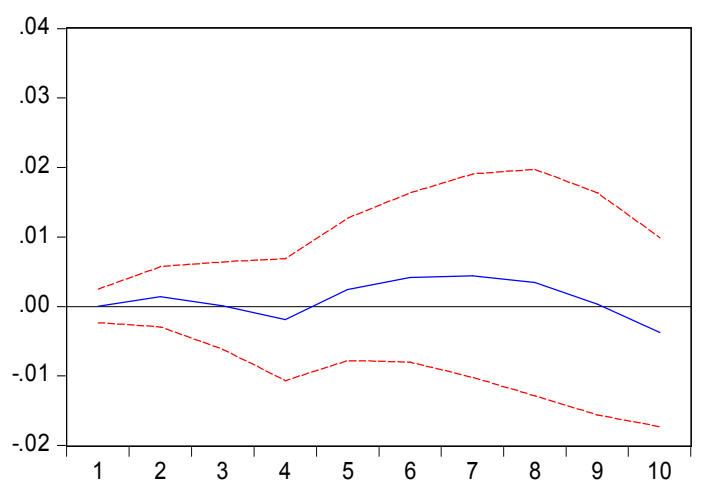

Figure 4. Impulse response curves of total agricultural machinery power and agricultural economic growth.

(4) The dynamic relationship between chemical fertilizer use and agricultural economic growth

The results of the impulse response analysis of fertilizer use and agricultural economic growth are shown in Figure 5 and Table 5. We first note that the cumulative response of lny and $\ln \mathrm{X}_{4}$ are positive, leading to the conclusion that agricultural chemical fertilizer use is conducive to agricultural economic growth. From Figure 5, we see that under the impact of $\ln \mathrm{X}_{4}$, lny shows a small positive amplitude during the entire reaction period, indicating that the use of chemical fertilizers is contribute to agricultural economic growth. It is important to note that lny showed a positive but not obvious effect over the entire reaction period, indicating that agricultural mechanization is helpful to agricultural economic output but not in a significant way. Moreover, during the reaction period, the shape of the response curve of $\ln \mathrm{X}_{3}$ is quite complex under the shock of lny, indicating that while the growth of China's agricultural economy contributes to improvement in the total power of agricultural mechanization but the influence mechanism is highly complicated.

Response of LNY to LNX3

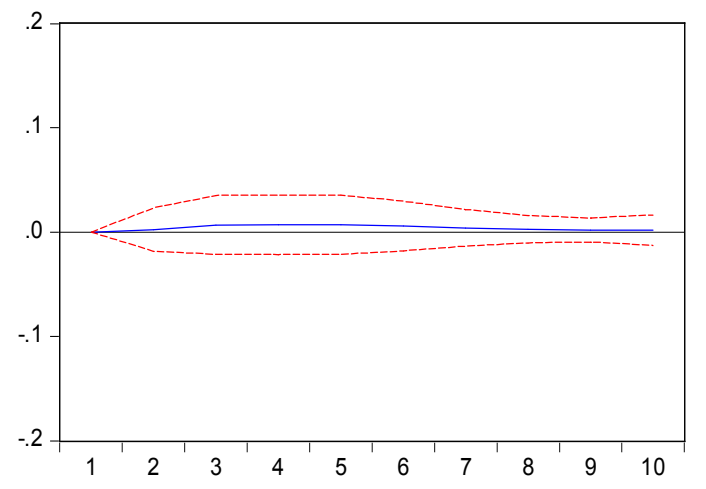

beneficial to the agricultural economy, but the effect is limited. Under the impact of $\ln y, \ln \mathrm{X}_{4}$ showed a significant downward trend during the reaction period. This finding may be related to strict control of chemical fertilizers by the Chinese government in recent years due to environmental pressure. Chemical fertilizers are an important agricultural production material and play an indispensable role in promoting the development of food and agricultural production. However, China currently is experiencing increasing costs and environmental pollution due to the indiscriminate and 
excessive application of chemical fertilizers. Consequently, in order to ensure the healthy supply of major agricultural products such as grain and the sustainable development of

Response of LNX4 to LNY

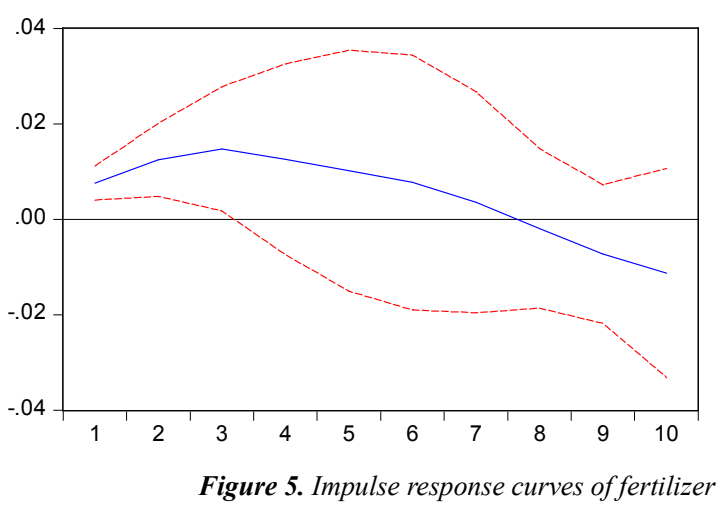

(5) The dynamic relationship between total sown area and agricultural economic growth

The results of the impulse response analysis of the total sown area and agricultural economic growth are shown in Figure 6 and Table 5. We first note that the performance of lny during the entire reaction period after being impacted by $\ln \mathrm{X}_{5}$ is negative, indicating that the increase in total sown area is not conducive to the development of the agricultural economy. We believe that the concept of modern agriculture is driven by

Response of LNX5 to LNY

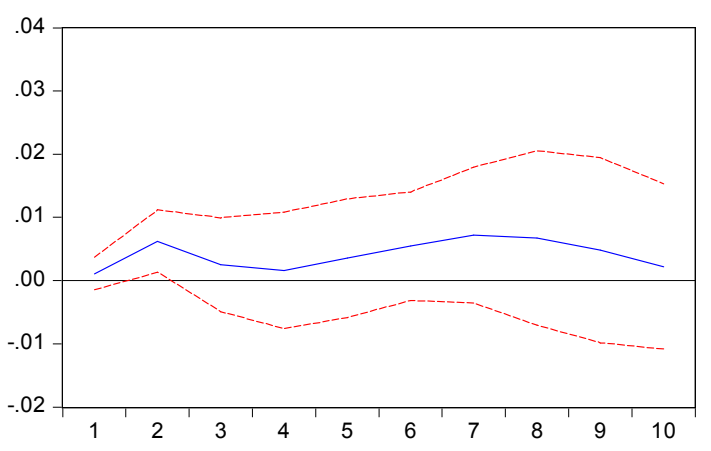

agriculture, the central government has increased control over the amount of chemical fertilizers in recent years, resulting in a decline in the response of $\ln \mathrm{X}_{4}$ under the impact of lny.

Response of LNY to LNX4

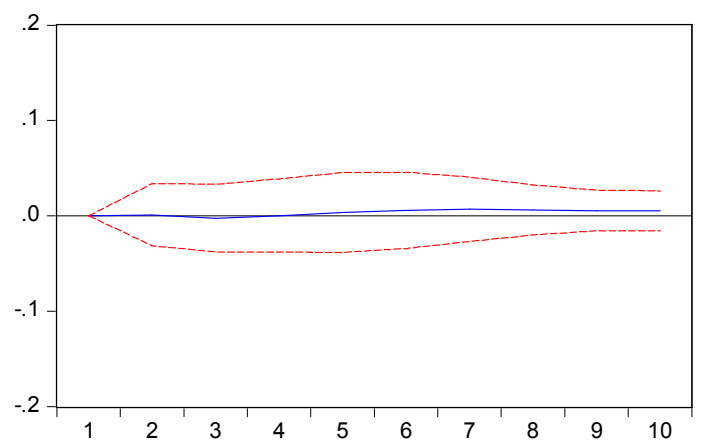

application and agricultural economic growth.

scientific and technological advances and improved management. Therefore, the concept of modern agriculture includes a reduction in the cultivated land that is used for agricultural development. Given the limited land resources, China should follow the path of efficient development. Based on regional characteristics and development advantages, different regions should focus on developing high value-added crops with comparative advantages to increase the efficiency and level of agricultural production.

Response of LNY to LNX5

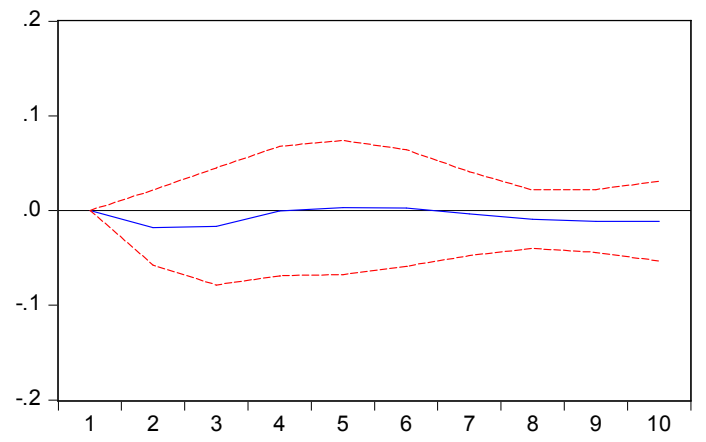

Figure 6. Impulse response curves of total sown area and agricultural economic growth.

(6) The dynamic relationship between educational level of the rural labor force and agricultural economic growth

The results of the impulse response analysis of rural labor's educational level and agricultural economic growth are shown in Figure 7 and Table 5. We first note that the cumulative reaction of lny under the impact of $\ln \mathrm{X}_{6}$ is positive but not obvious (0.023), indicating that the optimization of human capital is conducive to development of the agricultural economy, but the effect is not significant. Human capital has long been considered a powerful driving force for agricultural economic development and social progress. Scholars believe that with the accumulation of human capital, the agricultural production possibilities frontier will gradually expand outward. Therefore, improvement in the level of human capital may contribute to the efficiency of various production factors and accelerate the transition of traditional agriculture to modern agriculture. The $\ln \mathrm{X}_{4}$ variable is negative during the reaction period under the impact of lny. This result may be a manifestation of the "Rural Human-Capital Trap." In rural areas, parents cover the full expense of their children's education. However, after receiving higher education, children generally leave the countryside to work in the city. Consequently, most of the human capital accumulated through investment in education by rural households does not remain in rural areas. This means that the cost of rural education investment is borne by rural areas, but the benefit inures to the city. This has led to asymmetries in the costs and benefits of education investment in rural areas. Rural education has produced positive externalities to urban economic development and negative externalities to rural economic development. The result of this phenomenon is a reduction in the average educational level of rural residents in response to development of the agricultural economy. 
Response of LNX6 to LNY

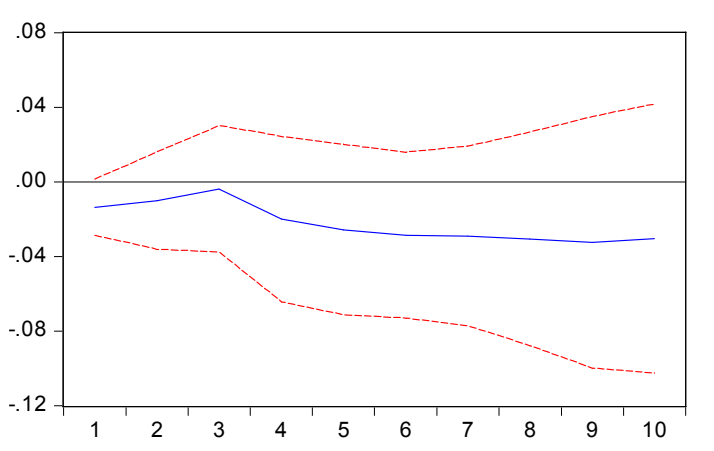

Response of LNY to LNX6

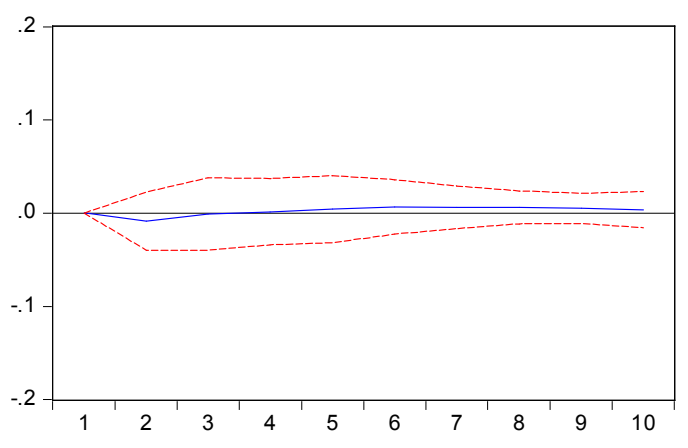

Figure 7. Impulse response curves of rural labor's educational level and agricultural economic growth.

\subsection{Variance Decomposition}

Variance decomposition is mostly used to describe the contribution ratio of different independent variables to the change in the dependent variable in a time series. Variance decomposition can express the relative importance of each disturbance item that has an impact on VAR model variables. The results of the variance decomposition of China's agricultural economic growth and various factors are shown in Table 6.

Table 6. Variance decomposition of Chinese agricultural economic growth and vector values of various elements.

\begin{tabular}{|c|c|c|c|c|c|c|c|c|}
\hline \multirow{2}{*}{ Period } & \multicolumn{8}{|c|}{ Variance Decomposition of Iny } \\
\hline & S. E. & lny & $\ln X_{1}$ & $\ln X_{2}$ & $\ln X_{3}$ & $\ln X_{4}$ & $\ln X_{5}$ & $\ln X_{6}$ \\
\hline 1 & 0.064 & 100 & 0 & 0 & 0 & 0 & 0 & 0 \\
\hline 2 & 0.105 & 93.796 & 2.322 & 0.009 & 2.979 & 0.128 & 0.713 & 0.053 \\
\hline 3 & 0.129 & 78.679 & 16.569 & 0.046 & 3.695 & 0.216 & 0.479 & 0.316 \\
\hline 4 & 0.149 & 70.068 & 25.615 & 0.034 & 2.737 & 0.732 & 0.362 & 0.451 \\
\hline 5 & 0.164 & 69.733 & 25.623 & 0.071 & 2.312 & 1.34 & 0.362 & 0.56 \\
\hline 6 & 0.171 & 71.064 & 23.861 & 0.171 & 2.133 & 1.669 & 0.474 & 0.627 \\
\hline 7 & 0.174 & 71.277 & 23.261 & 0.314 & 2.113 & 1.795 & 0.577 & 0.663 \\
\hline 8 & 0.175 & 70.491 & 23.526 & 0.431 & 2.371 & 1.812 & 0.688 & 0.682 \\
\hline 9 & 0.178 & 70.093 & 23.557 & 0.508 & 2.678 & 1.752 & 0.743 & 0.67 \\
\hline 10 & 0.184 & 70.109 & 23.327 & 0.556 & 2.903 & 1.729 & 0.737 & 0.639 \\
\hline Average & 0.149 & 76.531 & 18.766 & 0.214 & 2.392 & 1.117 & 0.513 & 0.466 \\
\hline
\end{tabular}

Among the factors influencing fluctuation in China's agricultural economic growth, the proportion contributed by agricultural economic growth itself in the first period was $100 \%$, and it gradually declined thereafter. However, at the $10_{\text {th }}$ period, agricultural economic growth still accounted for $70.109 \%$ of the total with an average of $76.531 \%$, indicating that China's agricultural economic growth fluctuation was mainly affected by itself. Of the other six factors, the proportion of material investment in the first period was 0 , and then gradually increased to $23.327 \%$ in the $10_{\text {th }}$ period, far exceeding the other indicators at the same time point, which reinforces the importance of material investment to China's agricultural growth. In fact, since the reform of the family contract responsibility system, irrigation and water conservancy facilities in most areas have fallen into disrepair and soil loss is severe. Large-scale and intensive production after land transfer still needs the financial support of government into the foreseeable fuure [41].

In addition, approximately $2.392 \%$ of agricultural economic growth fluctuations can be explained by changes in the total power of agricultural mechanization, $1.117 \%$ by chemical fertilizer use, $0.513 \%$ by total area under cultivation, $0.466 \%$ by rural labor's educational level, and $0.214 \%$ by the size of the agricultural labor force. On average, the contribution ratio of these indicators is relatively small, and the specifics of their contribution to economic growth are not well defined. With the process of modernization, agricultural development will depend less on investment and more on the advances in science and technology and the accumulation of human resources capital. Therefore, for future development, the government needs to increase investment in the research and development of agricultural science and technology and enhance job training to improve the quality of the agricultural labor force, which efforts will transform the workforce into human capital with immense potential.

\section{Conclusions and Suggestions}

\subsection{Conclusions}

The key to sustaining the growth of China's agricultural economy today is the financial support of the government. With the rapid development of science and technology, the era when China's agricultural production was highly dependent on the labor force has quietly passed. An excessive increase in the agricultural labor force may restrict economic growth. With the concept of sustainable development taking root in people's minds, agricultural production will depend less on the exploitation of land resources and the use of chemical 
fertilizers. In addition, the level of agricultural mechanization of China is generally low, which is also a restricting factor for economic development. Science and technology along with management capability are playing an increasingly important role in agricultural production, so improving the quality of the agricultural labor force will be an important factor in promoting the rapid development of the agricultural economy.

\subsection{Policy Recommendations}

(1) Increase financial support for agricultural development, and simultaneously optimize the agricultural fiscal expenditure structure and strengthen management. According to the empirical results presented in this paper, China's agricultural economic development is still heavily dependent on material inputs. However, the integration of agriculture-related funds started relatively late in China; therefore, there are many problems associated with their management, such as the inefficient use of funding ${ }^{[42]}$. To enable future development, the government needs to continue to increase financial fund investment in the agricultural sector to ensure adequate funding for agricultural development and stimulate enthusiastic among agricultural producers. The government also needs to strengthen the assessment of local agriculture financial utilization funds and improve the precise management of capital utilization. Finally, an effective oversight mechanism is needed to ensure effective implementation of these financial support measures and efficient use of funds.

(2) Develop high-end agricultural machinery and ensure the intensive operation of farmland. Mechanization is an important symbol of modern agriculture. To enable future development, China should increase investment in agricultural mechanization and strengthen scientific research on agricultural machinery. China's agricultural machinery industry started late and with a low baseline. Due to the low level of development and the backwardness of science and technology, China's agricultural machinery industry depends heavily on foreign countries in many key areas and is even nonexistent in many important areas. We think that the development of the agricultural machinery industry requires not just an increase in financial support, but more importantly, the strengthening of the research in this field and a greater reliance of the industry on science and technology. Thus, the government not only needs to purchase large quantities of foreign advanced technology but also needs to promote independent innovation. The government should rely on the status quo and characteristics of China's agricultural development, make efforts to develop agricultural machinery in key areas, and strive to increase knowledge and technology in the industry. China also needs to improve the efficiency and ecologicalization of agricultural machinery production so that agricultural machinery can be built in a more economical way.

(3) Make reasonable use of chemical fertilizers to ensure sustainable development of the agricultural economy. First, adopt a variety of agricultural production measures. In order to continuously reduce the amount of agricultural chemical inputs, producers should be encouraged to use diversified modern methods to ensure sustainable growth of the agricultural output value per unit of sown area. For example, the infrastructure construction such as water conservancy and electrification could be accelerated, and all provinces and cities should fully consider their agricultural conditions to construct agricultural infrastructure that is rationally laid out and easily managed. At the same time, producers should make efforts to promote agricultural mechanization vigorously, use the appropriate agricultural machinery based on terrain and crop type, and continuously improve production efficiency to compensate for the efficiency lost as a result of the reduction in agricultural chemicals. Second, improve the effectiveness of agricultural chemicals. The government needs to increase the scientific and technological content of agricultural chemicals and to focus on researching and developing agricultural chemicals with low toxicity and pollution. Finally, the government needs to make an overall plan based on different areas by assessing the status of non-point source pollution and specifics of agricultural resources and the environment in different regions and subsequently establish a clear objective of reducing agricultural chemicals, develop differentiated goals and policies based on different regions, and accelerate the development of environmental and resource-friendly agriculture.

(4) Further strengthen rural education and increase the accumulation of China's agricultural human capital. From the research conclusions of this paper, we can see that improved rural education has a positive impact on the growth of China's rural economy. Compared with developed countries, the average level of education in rural China is low and imbalanced. This low level of education is partly due to the government's failure to invest sufficiently in rural education, whereas significant educational resources are allocated to urban residents. There also continues to be backwards ideas that farmers do not need to be highly educated. Therefore, the government should significantly strengthen rural education and increase financial support to provide a strong educational environment for rural residents, which will promote the growth of human capital in rural areas. In addition, in order to avoid the "Human-Capital Trap" in rural areas, the government should loosen the restrictions on migration of talent back to the villages, and provide the financial support to create an attractive environment in the country that will encourage talent to return.

\section{Acknowledgements}

The authors are grateful for the financial support provided by the China Scholarship Council, the National Natural Science Foundation of China (Grant No. 41401634) and the Fundamental Research Funds from the Central Universities (Grant No. 2016B31914).

\section{References}

[1] Catherine J Morrison Paul, Donald S Siegel. Scale Economies and Industry Agglomeration Ezternalities: A Dynamic Cost Function Approach [J]. The American Economic Review, 1999. 
[2] Vernon J Henderson, Zmarak Shalizi. Geography and Develop [R]. NBER, Working Paper, 2001.

[3] Brown L R, Halweil B. China's Water Shortage Could Shake World Food Security [J]. World Watch, 1998, 11 (4): 7-8.

[4] Du J, Liu Y. Human Capital Investment and Agricultural Economic Growth: An Empirical Analysis Based on the China's Provinces Data [J]. Economic Review, 2008 (3): 22-27. (in Chinese).

[5] Pan D, Yin R Y. Relationship Between Water Resource and Agricultural Economic Growth in China: Research Based on Panel VAR [J]. China Population, Resources and Environment, 2012, 22 (1): 161-166. (in Chinese).

[6] Xu C X, Lin J T, Song M. Research on the spatial effects of water and soil matching degree on economic growth of regional agriculture based on empirical analysis during 2003-2013 in China $[J]$. China Population, Resources and Environment, 2016, 26 (7): 153-158. (in Chinese).

[7] $\mathrm{Mi} \mathrm{H} \mathrm{M,} \mathrm{Lu} \mathrm{Q.} \mathrm{Effect} \mathrm{of} \mathrm{water} \mathrm{investment} \mathrm{on} \mathrm{agricultural}$ economic growth in Shanxi Province [J]. Journal of China Agricultural University, 2015, 20 (1): 262-267. (in Chinese).

[8] Li Q, Chen H M, Wang Y P. The Interactive Effect of Agricultural Water and Agricultural Economic Growth in Xinjiang [J]. Resources Science, 2014, 36 (8): 1679-1685. (in Chinese).

[9] Matsuyama K.. Agriculture Productivity, Comparative Advantage, and Economic Growth [J]. Journal of Economic Theory, 1992 (2): 317-334.

[10] Antle Schick. The Private R\&D Investment Response to Federal Design and Technical Competitions [J]. American Economic Review, 1993: 178.

[11] J. A. Mollot. Public Finance and Public Policy: Responsibilities and Limitations of Government [M]. New York: Cambridge Univ. Press, 2003.

[12] Peter Timmer. Agriculture and Pro-Poor Growth [M]. Center for Global Development, 2005.

[13] Li X S, Ran G H. Fiscal Decentralization, Agricultural Economic Growth and Urban-Rural Income Disparity [J]. Journal of Agrotechnical Economics, 2013 (1): 86-94. (in Chinese).

[14] Lyu C L, Jiang H C. A Study on Effects of Fiscal Expenditure for Agriculture on Agricultural Economic Growth-Based on 1952-2012Data Analysis [J]. The Theory and Practice of Finance and Economics, 2016, 37 (6): 90-95. (in Chinese).

[15] R. Solow. Technical Change and the Aggregate Production Function. The Review of Economics and Statistics, 1957, 39 (3): 312-320.

[16] Denison, Edward F. Why rowth rates differ: post-war experience in nine westem countries. Washington: Brookings Institution, 1967.

[17] P. Romer. Increasing Returns and Long-Run Growth. Journal of Political Economy, 1986, 94 (5): 1002-1037.

[18] Huang J, Rozelle S. Market development and food consumption in rural china [J]. Economic Review, 1998, 9 (1): $25-45$.

[19] Yao Y T, Chen W M, Li x L. Research of Relationship Between
Environmentally-friendly Agricultural Technology Innovation and Agricultural Economic Growth [J]. China Population, Resources and Environment, 2014, 24 (8): 122-130. (in Chinese).

[20] Liu Y P, Zhong S C. The Impact of the Direction of Technological Progress, the Substitution Elasticity between Capital and Labor on the Growth of Agricultural Economics [J]. Collected Essays on Finance and Economics, 2016 (9): 3-9. (in Chinese).

[21] Bao H J, Liu D G, Chen Y. The Empirical Test of the Relationship between Agricultural Mechanization and Agricultural Economic Growth [J]. Statistics \& Decision, 2012 (21): 139-141. (in Chinese).

[22] Wu L H, Peng Y W. Research on Dynamic Correlation between Agricultural Science and Technology Input and Agricultural Economic Growth [J]. Journal of Agrotechnical Economics, 2013 (12): 87-93. (in Chinese).

[23] Wu X L, Zhang J B, Feng J H. Technological Innovation, Spillover and Agricultural Economic Growth of Agricultural Scientific Institution Technological Innovation of Agricultural Scientific Institutions, Spillover and Agricultural Economic Growth [J]. Science and Technology Management Research, 2016, 36 (17): 79-86. (in Chinese).

[24] Schultz, T. W. Investment in human capital. American Economic Review, 1961 (51): 1-17.

[25] Mankiw, N. G., Romer, D. and Weil, D. N. A Contribution to the Empirics of Economic Growth. Quarterly Journal of Economics, 1992 (107): 407-437.

[26] Barro, R. J. Human Capital and Growth. American Economic Review, 2001 (91): 12 17.

[27] Bloom D. E., D. Canning and J. Sevilla. The Effect of Heath on Economic Growth: A Production Function Approach [J]. World Development, 2004, 32 (1): 1-13.

[28] Du J, Liu Y. Analysis of Factors Contributing to the Agricultural Economic Growth: Physical Capital, Human Capital, or Foreign Trade? [J]. Nankai Economics Studies, 2010 (3): 73-89. (in Chinese).

[29] Sun Y P, Zhou X. Research on the Influence of Heterogeneous Human Capital on China's Agricultural Economic Growth-Based on Provincial Panel Data [J]. Journal of Agrotechnical Economics, 2015 (4): 108-119. (in Chinese).

[30] Patrick, G. F. and Kehrberg, E. W. Costs and returns of education in five agricultural areas of eastern Brazil. American Journal of Agricultural Economics, 1973 (55): 145-153.

[31] Phillips, J. M. and Marble, R. P. Farmer education and efficiency: A frontier production function approach. Economics of Education Review, 1986 (5): 257-264.

[32] Islam, N. Growth Empirics: A panel Data Approach. Quarterly Journal of Economics, 1995 (4): 1127-1170.

[33] Wu J, Chen J. An Empirical Study on the Relationship between Income Gap between Urban and Rural Residents and Agricultural Economic Growth [J]. Journal of Agrotechnical Economics, 2010 (12): 25-30. (in Chinese).

[34] Yao X B, Luo G Q, Ning R F. Research on the Regional Effect of Urbanization and Agricultural Economic Growth-An Empirical Analysis Based on PVAR Model [J]. Journal of Southwest University ( Social Sciences Edition), 2016, 42 (3): 60-68+190. (in Chinese). 
[35] Sun H M, Hu D X, Liu L Y. The effect of Agricultural Export and Import on Jilin's Agricultural Economic Growth [J]. Chinese Journal of Agricultural Resources and Regional Planning, 2016, 37 (1): 174-180. (in Chinese).

[36] Ji Q H. An Empirical Study on the Relationship Between Education Level and Agricultural Economic Growth-Based on Rural Panel Data of 30 Provinces and Cities in China [J]. Chinese Journal of Agricultural Resources and Regional Planning,, 2017, 38 (5): 101-107. (in Chinese).

[37] Zhang Y Q, Zhou Y H, Yi Z Y. Rural Financial Development, Agricultural Economic Growth and Farmers' Income Increase-An Empirical Analysis Based on Spatial Econometric Model [J]. Journal of Agrotechnical Economics, 2013 (11): 50-56. (in Chinese).

[38] Liu J Q, Xu N, Liu D Y. A Study on the Non-linear Correlative Mechanism of Rural Financial Development and Agricultural Economic Growth: Theoretical Analysis and Empirical Test [J]. Journal of Nanjing Agricultural University
(Social Sciences Edition), 2016, 16 (2): 134-143+156. (in Chinese).

[39] Wang H, Wang E X. Research on the relationship between agricultural industrial structure optimization and agricultural economic growth - Case of Hunan province [J]. Journal of Central South University of Forestry \& Technology (Social Sciences), 2017, 37 (6): 119-124. (in Chinese).

[40] Smis A C. Macroeconomics and reality [J]. Econometrica, 1980 (48): 1-48.

[41] Song S L, Wang X L. Analysis of the Impact of China's Agricultural Economy Growth Moment under the New Normal-Based on the Statistics of Heilongjiang Province from 1990 to 2015 [J]. Journal of Agrotechnical Economics, 2017 (7): 102-108. (in Chinese).

[42] Mao S P, Ji X X. The Financial Effective Inputs to Agriculture and Countryside: Searching a Path [J]. Reform, 2017 (11): 136-147. (in Chinese). 